\title{
Erratum to: Assessing environmental and occupational risk factors for lung cancer in Mexican-Americans
}

\author{
Michelle K. McHugh • Sumesh Kachroo • Mei Liu • \\ Anthony M. D'Amelio Jr. • Qiong Dong • Waun Ki Hong • \\ Anthony J. Greisinger $\cdot$ Margaret R. Spitz $\cdot$ Carol J. Etzel
}

Published online: 7 April 2011

(C) Springer Science+Business Media B.V. 2011

\section{Erratum to: Cancer Causes Control (2010) 21:2157-2164} DOI 10.1007/s10552-010-9635-1

The authors erroneously included the statement that cases were excluded if they had prior lung disease, which is incorrect. The sentence should read that cases were not excluded if they had prior lung disease as the cases were recruited within a large multi-ethnic study that queried prior physician diagnosis of COPD, pneumonia, asthma, and hay fever.

The online version of the original article can be found under doi: 10.1007/s10552-010-9635-1.

M. K. McHugh · S. Kachroo - M. Liu - A. M. D’Amelio Jr. · Q. Dong · M. R. Spitz · C. J. Etzel ( $₫)$

Department of Epidemiology, The University of Texas MD

Anderson Cancer Center, 1155 Pressler Boulevard, Unit 1340,

Houston, TX 77030, USA

e-mail: cetzel@mdanderson.org

S. Kachroo · M. Liu

The University of Texas School of Public Health, Houston, TX 77030, USA

A. M. D’Amelio Jr.

Biomath/Biostatistics Program, The University of Texas

Graduate School for Biomedical Sciences, Houston,

TX 77030, USA

W. K. Hong

Division of Cancer Medicine, The University of Texas MD

Anderson Cancer Center, Houston, TX 77030, USA

\section{A. J. Greisinger}

Kelsey Research Foundation, Houston, TX 77005, USA 